
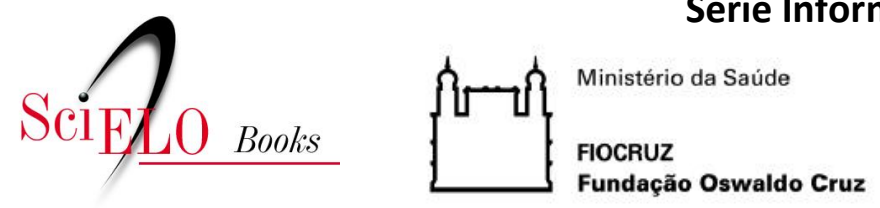

OBSERVATÓRIO COVID-19

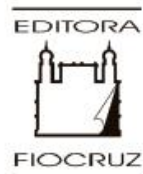

\title{
Num mundo em mudança, desafios gigantescos apresentação
}

\author{
Paulo Marchiori Buss \\ Luiz Eduardo Fonseca
}

\section{SciELO Books / SciELO Livros / SciELO Libros}

BUSS, P.M., and FONSECA, L.E. eds. Num mundo em mudança, desafios gigantescos: apresentação. In: Diplomacia da saúde e Covid-19: reflexões a meio caminho [online]. Rio de Janeiro: Observatório Covid 19 Fiocruz; Editora FIOCRUZ, 2020, pp. 13-26. Informação para ação na Covid-19 series. ISBN: 978-65-5708-029-0. https://doi.org/10.7476/9786557080290.0001.

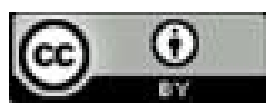

All the contents of this work, except where otherwise noted, is licensed under a Creative Commons Attribution $\underline{4.0 \text { International license. }}$

Todo o conteúdo deste trabalho, exceto quando houver ressalva, é publicado sob a licença Creative Commons Atribição 4.0.

Todo el contenido de esta obra, excepto donde se indique lo contrario, está bajo licencia de la licencia Creative Commons Reconocimento 4.0. 


\section{Num Mundo em Mudança, Desafios Gigantescos}

apresentação

Paulo Marchiori Buss e Luiz Eduardo Fonseca

P ela capacidade de ceifar vidas humanas, destruir economias, mexer com as emoções de milhares de pessoas, produzindo medo e solidão, de expandir-se por todos os países do mundo e deixar imensas dúvidas sobre o futuro, a pandemia da Covid-19 é um dos maiores acontecimentos de repercussão global dos últimos cem anos da história da humanidade. Na realidade, o transcurso do processo, desde seu início até aqui, mostrou que se trata, mais do que de uma pandemia, de uma sindemia (Horton, 2020a), permeada por uma infodemia (Opas, 2020). Em termos de enfermidade, só é comparável com a vasta e mortal pandemia pelo vírus influenza que, de janeiro de 1918 a dezembro de 1920, infectou cerca de 500 milhões de pessoas, ou aproximadamente um quarto da população mundial à época, deixando um saldo de 17 a 50 milhões de vidas perdidas. A I Guerra Mundial, em cujo contexto social e temporal se insere a gripe "espanhola", teria marcado, para o genial historiador inglês Eric Hobsbawm, o fim do longo século XIX (I789-1914) e o início do que ele denominou o "breve século XX", epíteto e subtítulo da sua admirável obra Era dos Extremos, que teria durado de 1914 até a queda da União Soviética, em 1991 (Hobsbawm, 1994).

Impossível discordar do célebre historiador marxista. Mas nos permitimos arriscar dizer que, embora a revolução tecnológica e a globalização pudessem vir a marcar o início do século XXI, que começou cronologicamente em 2000-200I, tais mudanças não foram suficientes para conduzir a grandes mudanças na ordem global. Contudo, se considerarmos o tempo histórico, ele estaria começando em 2020, com a pandemia pelo Sars-CoV-2 e suas imensas consequências detectadas na forma de viver e conviver, embora ainda não de todo dimensionadas, já que estamos, a nosso ver, apenas a meio caminho nesta pandemia. 
A pandemia está longe de terminar, segundo muitos especialistas, e pode se estender por um a dois anos ou até se transformar numa enfermidade endêmica com surtos epidêmicos, dependendo do tipo de imunidade que deixa, seja por sua infecção natural, seja pela imunidade adquirida por uma vacina - que não temos ainda e não sabemos que capacidade imunogênica terá e que duração de resposta imune deixará.

Por essa razão, denominamos o livro como Diplomacia da Saúde e Covid- 19: reflexões a meio caminho. A meio caminho por duas razões: porque realmente estamos a dez meses de sua chegada e ela se encontra ainda em expansão no mundo e recrudescendo onde já passou, deixando um triste rastro de mortes e sequelas; e porque, portanto, a resposta que o conjunto de atores da cena política e técnica internacional, que temos a pretensão de examinar, também se encontra a meio caminho.

Desde que eclodiu a pandemia de Covid-19, o Centro de Relações Internacionais em Saúde da Fundação Oswaldo Cruz (Cris/Fiocruz) mobilizou todos seus profissionais para o acompanhamento sistemático do desenvolvimento da enfermidade em todo o mundo. Durante 15 semanas consecutivas, de abril a agosto de 2020, os profissionais do Cris examinaram e produziram informes semanais sobre a resposta à pandemia de Covid- 9 no campo da diplomacia da saúde, nos organismos e iniciativas multilaterais globais e regionais.

Paradoxalmente, um minúsculo RNA que não respeitava fronteiras, que se mantiveram forçosamente abertas à sua propagação, obrigou ao fechamento das fronteiras geopolíticas a seus potenciais portadores, restringindo ao mínimo sua mobilidade. Enquanto se fechavam as fronteiras para conter o vírus, um multilateralismo global ameaçado e multilateralismos regionais se mobilizavam (ou não) para cooperar, visando ao controle do vírus. É desta última questão que tratamos neste volume virtual de 22 capítulos: a resposta do multilateralismo global e regional, por meio da diplomacia da saúde, à pandemia da Covid-19, causada pelo vírus Sars-CoV-2, e suas circunstâncias.

As três partes nas quais se divide a coletânea e seus diversos capítulos são complementares entre si: quando reunidos dão, simultaneamente (no tempo histórico e na geografia), a visão de cada região e a visão mundial, dado o enfoque sobre as institucionalidades multilaterais global e regionais.

Trata-se de um típico instant book,' ou seja, um livro que pretende contribuir com um retrato instantâneo e assumidamente parcial de um fenômeno ou acontecimento

\footnotetext{
I Instant book (livro instantâneo) é um termo usado no mundo editorial para designar um livro produzido e publicado muito rapidamente para atender à demanda da sociedade. Instant books buscam organizar e divulgar o conhecimento (parcial) sobre o fenômeno - de seu início até o momento da publicação.
} 
(Freitag, 1987), neste caso, da resposta à pandemia. Entre os exemplos mais famosos deste tipo de publicação estão os muitos instant books produzidos logo após o afundamento do Titanic, em 1912, que venderam milhares de exemplares de porta em porta e nas esquinas das grandes cidades americanas, europeias e, é claro, do Reino Unido. Estaríamos nós produzindo um instant book não sobre o afundamento físico de um navio, mas sobre o naufrágio de uma forma de viver da nossa humanidade comum, moldada no "breve século XX" e nas últimas décadas?

Em seu artigo de tom quase melancólico, na edição do New York Times de novembro de 1987, Freitag decretava que os tempos dos instant books haviam acabado. Sim, possivelmente, àquela época, terá sido um diagnóstico próximo do correto. Contudo, hoje em dia, com a internet e os e-books, que são de acesso instantâneo, renascem os instant books virtuais, e o volume que o leitor tem em mãos, ou na sua tela, é assumidamente um deles. ${ }^{2}$

Embora intuitivamente possamos reconhecer a necessidade de um "multilateralismo" ativo e generoso para enfrentar uma enfermidade desta natureza e envergadura, por meio de uma ativa "diplomacia da saúde", ou a importância da Covid-19 nas discussões no campo da "saúde global", é decepcionante quando pesquisamos estes termos, isoladamente ou grupados em trio e pares, associados com a enfermidade, no potente site de artigos da Organização Mundial da Saúde (OMS) sobre a enfermidade, que já contém mais de 60 mil artigos. Muitos poucos artigos estão disponíveis, o que justifica mais ainda este apanhado de ensaios sobre a "diplomacia da saúde" em tempos de pandemia.

Para fazê-lo, foram acompanhadas, descritas e analisadas as respostas à pandemia nas diversas instâncias e agências das Nações Unidas, com particular foco na OMS, como não poderia deixar de ser, incluindo a Secretaria-Geral, o Conselho de Segurança, o Conselho Econômico e Social (Ecosoc), o Conselho de Direitos Humanos e outros; nas diversas regiões e alguns países do mundo (América Latina e Caribe, África, Europa, Oriente Médio e Ásia-Pacífico, Brasil, China e Estados Unidos); em organizações ou iniciativas multilaterais, como Brics (Brasil, Rússia, Índia, China e África do Sul), G20, Organização para a Cooperação e Desenvolvimento Econômico (OCDE) e Movimento dos Não Alinhados e G77; e instituições financeiras internacionais - Fundo Monetário Internacional (FMI), Banco Mundial (Banco Mundial) e Banco Interamericano de Desenvolvimento (BID). A descrição e análise

\footnotetext{
${ }^{2}$ Um exemplo de instant book tradicional, impresso, e sobre a pandemia, é o livro de Richard Horton (2020), The Covid- 19 Catastrophe, lançado pela Polity Press.
} 
dessas respostas está reunida no conjunto de 14 capítulos que constitui o núcleo duro do livro, a Parte II, denominada “Diplomacia da Saúde e Covid-19”.

Como o conjunto de leitores e interessados a que se destina este livro é amplo e variado - de profissionais da saúde a diplomatas, de especialistas em saúde global e diplomacia da saúde a ativistas sociais, entre outros -, introduzimos também conteúdos relativos ao que chamamos "A Doença e suas Circunstâncias" nos seis capítulos reunidos na Parte I deste volume. Para bem fazê-lo, selecionamos alguns temas transversais - geopolítica, crise humanitária, economia, insumos, a doença propriamente dita - e convidamos especialistas de grande envergadura para abordá-los. Ou seja, uma abordagem compatível com a visão hoje dominante de que estamos enfrentando uma pandemia sindêmica (Horton, 2020b).

O embaixador Celso Amorim faz, com a maestria e elegância de sempre, uma reflexão sobre a geopolítica pós-pandemia. Menciona, de partida, a ultrapassagem dos Estados Unidos da América (EUA) pela China como a maior economia do planeta, que terá amplos reflexos também no plano político. ${ }^{3}$ Nesse sentido, aponta para o acréscimo do chamado "poder brando" chinês ou o ativismo diplomático em ações de cooperação em relação à pandemia. Chama a atenção, ademais, para o fato de que não é possível menosprezar o papel e a ambição da Rússia, preferindo, por isso, referir-se a um tripé, em que três superpotências buscariam equilíbrios variáveis. Assinala, ainda, que a União Europeia continuará a ter peso relevante, como ficou demonstrado na poderosa resposta política, fiscal e monetária estruturada para a reconstrução pós-pandemia.

Quanto ao papel da América Latina e Caribe (ALC) na construção da "nova ordem", Amorim entende que há duas opções. A primeira, com cada país atuando isoladamente, correndo o risco de uma subalternidade que os deixará reféns dos interesses de uma das grandes potências. A segunda, atuando de forma tão unida quanto possível, capacitandose para os grandes desafios econômicos e tecnológicos do presente e do futuro. O autor finaliza alertando que questões como clima, pandemia e emprego ocuparão o centro dos debates globais e, visionário, lembra que, como sempre, a história apenas coloca os problemas, cabendo aos seres humanos, devidamente conectados, resolvê-los.

No capítulo seguinte, Trindade, Buss e Paes-Sousa tratam da crise sanitária e humanitária imposta pela pandemia da Covid-19, procurando responder se seria ela um fenômeno inevitável diante da relação que os humanos mantêm com os diversos ecos-

\footnotetext{
3 O que alguns têm denominado "armadilha de Tucídides", parodiando o processo que levou à Guerra do Peloponeso, entre Grécia e Esparta, entre 43 I e 404 a.C.: a ultrapassagem de uma potência dominante por uma emergente.
} 
sistemas e as demais espécies animais e vegetais. Ou, em uma abordagem simplificada, o desfecho episódico - porém recorrente - da forma como se produzem e se consomem bens e serviços no mundo.

Dois temas, entre muitos outros, têm recebido particular atenção nas discussões políticas e técnicas durante a pandemia. As reflexões apresentadas por Gadelha indicam a urgência em apontar caminhos para o futuro, pois a realidade da pandemia, em seu curso natural, tende a agravar a crise e as vulnerabilidades estruturais. Propõe-se, a partir da concepção do Complexo Econômico-Industrial da Saúde (Ceis), uma abordagem passível de ser generalizada para viabilizar um padrão de desenvolvimento norteado pela equidade, pelo bem-estar e pelo dinamismo econômico e tecnológico. Os direitos sociais e à vida são apresentados como parte essencial da solução para a saída da crise, constituindo uma alavanca para sua superação estrutural.

Em vez de um "novo normal" que reproduza nossa desigualdade e as assimetrias globais, podemos construir uma agenda mínima de transformações estruturais que supere as tendências em curso, evidenciadas na pandemia do novo coronavírus, de acirramento da exclusão e da progressiva barbárie social, para que possamos construir um país e uma sociedade melhores, comprometidos com as pessoas que aqui vivem e que são os responsáveis pela riqueza aqui gerada.

A pandemia aumentou a demanda por intervenções que ofereçam resultados na sua contenção ou controle. Embora a ausência de tecnologias levasse à adoção de uma série de medidas não farmacológicas, as desigualdades e iniquidades no acesso a produtos essenciais de saúde já existentes ou em movimento ascendente remetem a décadas de discussão nos mais variados foros mundiais. Bermudez e Leineweber destacam no capítulo 4 deste volume que o histórico recente reflete a coexistência de iniciativas globais e multilaterais, com nítido contraste entre as tecnologias de saúde como bens públicos globais e a disputa acirrada no mercado promovida por interesses econômicos nacionais ou regionais. A competição financeira e as barreiras representadas pela propriedade intelectual ou monopólios decorrentes são obstáculos à cooperação solidária liderada pelas Nações Unidas e pela OMS. A potencialidade de bens públicos globais se revela na perspectiva dos direitos humanos, em uma proposta para o "novo normal" pós-pandemia com acesso universal.

Dado o interesse demonstrado por muitos profissionais em debates dos quais muitos dos autores deste livro participaram, destacamos dois temas de natureza biológica, clínica e epidemiológica, tratados por especialistas de alto nível convidados para desenvolvê-los. Santini de Oliveira, Matos e Siqueira, no capítulo sobre aspectos clínicos e laboratoriais da Covid-19, registram que o Sars-Cov-2, o terceiro coronavírus capaz de causar 
doença humana grave surgido nas últimas duas décadas, disseminou-se rapidamente pelo mundo a partir de Wuhan, na China, onde os primeiros casos de pneumonia intersticial foram relatados em dezembro de 20 I 9. A Covid- 19 foi declarada pandemia pela OMS em março de 2020. O vírus transmite-se pessoa a pessoa por vias direta (gotículas e fômites) e indireta (contato com superfícies contaminadas), causando amplo espectro de manifestações clínicas, desde quadros assintomáticos até quadros respiratórios graves, sepses e óbito. Ainda há muitas lacunas no conhecimento sobre a patogênese e a resposta imune à infecção. O diagnóstico etiológico, importante ferramenta para a vigilância em saúde, é realizado pela detecção de material viral em secreções respiratórias. O tratamento é sintomático e de suporte, e as medidas de prevenção são não farmacológicas, apesar de mais de duas centenas de produtos candidatos vacinais estarem em diferentes fases de desenvolvimento.

Segundo Schneider e Santini de Oliveira, autoras do capítulo sobre a relação entre saúde única e a pandemia, é imprescindível entender que, no planeta compartilhado em que vivemos, o que acontece num local pode afetar a todos e temos que aprender a viver em harmonia entre os seres humanos, respeitando os animais e o meio ambiente. Entender que estamos interligados e a importância da colaboração entre as diferentes disciplinas é a base do conceito de saúde única, que pode fornecer novas ferramentas para pesquisa, serviços eficazes e políticas em benefício da humanidade e dos animais, conservando o ambiente para as gerações atuais e futuras.

Os exemplos da peste, da varíola, da influenza em 1918 e da Covid- 19 demonstram que as epidemias fazem parte da história da humanidade. Para que ocorra uma pandemia é necessária a conjunção de diversos fatores, relacionados ao agente infeccioso, a pessoas, a animais e ao ambiente, considerado não apenas no contexto físico, mas também na forma como o homem ocupa o espaço e como se relaciona socialmente. Para diminuir as probabilidades de que ocorram novos eventos na interface animal-humano-ambiente, a abordagem com enfoque de saúde única pode ser usada tanto na predição como na prevenção e na detecção precoce.

A Parte II do livro trata das questões relativas às respostas multilaterais globais e regionais à pandemia, núcleo duro do que denominamos diplomacia da saúde. Seus diversos capítulos examinam, no mesmo período - as semanas de abril a agosto -, a resposta das diversas organizações multilaterais e internacionais, globais e regionais, e de países-chave no cenário global, propiciando ao leitor um rico panorama, que permite inclusive identificar aquelas mais adequadas e oportunas, e onde foram observadas falhas mais importantes. 
Mais que um exame exaustivo, Alcázar oferece, no capítulo sobre a resposta das Nações Unidas sugestivamente intitulado "Prelúdio em dó maior", um olhar impressionista sobre os diferentes matizes da resposta do sistema das Nações Unidas à Covid-19. Para tanto, faz um sobrevoo, identificando os órgãos principais do sistema, as agências especializadas, os programas e fundos, os comitês e conselhos, que parecem como as complexas partes de um relógio.

A resposta das Nações Unidas aborda a dimensão sanitária, a emergencial e a de retomada, pós-pandemia. Como exemplo das ações desenvolvidas nessas três dimensões, o autor escolheu exibir as ações levadas a cabo pela OMS, a Organização das Nações Unidas para a Alimentação e a Agricultura (FAO) e a Organização Internacional do Trabalho (OIT), três agências especializadas diretamente envolvidas no encaminhamento de soluções para a Covid-19. Como exemplos, escolheu as ações levadas adiante por fundos e programas, especificamente o Programa das Nações Unidas para o Desenvolvimento (Pnud) e a Agência da ONU para Refugiados (Acnur). Finalmente, se deteve a contemplar o coração do sistema, representado pela Assembleia Geral das Nações Unidas (AGNU), o Ecosoc, o Conselho de Direitos Humanos, que depende da AGNU, e o Conselho de Segurança. O capítulo explora, portanto, o que foi, até o final do primeiro semestre de 2020, a resposta desse sistema multilateral à Covid- 19.

As principais atividades de resposta e coordenação global da OMS e de seus escritórios regionais, com destaque para a Organização Pan-Americana da Saúde (Opas), são apresentadas no capítulo em que Galvão faz uma seleção de eventos, iniciativas e documentos que representam áreas temáticas centrais e elementos-chaves da resposta. Esse é o evento de saúde pública de preocupação internacional (PHEIC) mais grave da história da OMS e representa um desafio ao Regulamento Sanitário Internacional e à governança da saúde pública global. Sua magnitude fez com que inúmeras medidas inovadoras fossem tomadas em diversos campos da saúde e de outros setores. O registro dessas atividades permitirá elaborar documentos sobre as lições aprendidas, as lacunas identificadas e, eventualmente, encontrar caminhos para melhor preparação no caso de eventos futuros, que não se restrinjam a mudanças na estrutura burocrática, mas sim envolvam transformações sociais por um mundo mais justo, amigável com a natureza e com melhor segurança humana. Galvão ressalta também as questões relacionadas às iniquidades em saúde, a necessária resposta intersetorial e considerações sobre questões ambientais, desenvolvimento sustentável, equidade, solidariedade e paz.

Minayo e Cazumbá contextualizam e descrevem cronologicamente as principais medidas tomadas pelo Banco Mundial, pelo FMI e pelo BID em resposta à pandemia. Realizam uma revisão dos documentos oficiais lançados por essas instituições e analisam 
criticamente os discursos que, aparentemente, trazem à tona poucas novidades em relação às velhas práticas de concessão de financiamentos. A atual pandemia é um dos maiores desafios que a humanidade enfrentou nos últimos tempos. Calcula-se que levará a grande aumento de pessoas vivendo na extrema pobreza. A extensão desse impacto social e econômico ainda é incerta. Mas não restam dúvidas de que a Covid- 19 provocou um choque mundial, com trágicas consequências para as populações mais vulneráveis. Diante desse panorama, as referidas instituições ampliaram seus mecanismos para mitigar os efeitos da pandemia. No entanto, parecem ter perdido a oportunidade de mudar o paradigma de suas práticas de financiamento aos países mais necessitados.

No capítulo sobre o Grupo dos Vinte (G20) e a OCDE, Fonseca analisa o desempenho dos grupos durante a pandemia da Covid-19. Ao fazê-lo, procura relacionar o G20 com outras instâncias multilaterais e suas relações, principalmente com a OCDE, com a qual tem estreita semelhança e colaboração, no tocante, principalmente, à ajuda internacional. O ensaio trata do paradoxo entre a declaração da cúpula do G20 e a declaração do encontro dos ministros da Saúde do G20: ao passo que a primeira se coloca ao lado do multilateralismo e oferece total apoio ao combate da pandemia e seus reflexos econômicos, a segunda, fruto do dissenso entre EUA e China, não assume posicionamento em relação a seu próprio objeto. O ensaio finaliza com uma reflexão sobre as pautas da economia e da saúde no G20, a partir da pandemia da Covid- 19.

Ungerer descreve brevemente a criação e o contexto histórico do Movimento dos Países não Alinhados (MNA) e do Grupo dos 77 (G77). Analisa os modos como ambos os grupos foram concebidos, como ultrapassaram os anos da Guerra Fria e como enfrentam os desafios de hoje, no cenário mundial. O MNA é a maior coligação de países depois das Nações Unidas e o G77 é a maior organização intergovenamental de países em desenvolvimento das Nações Unidas. Ambos estão mobilizados para enfrentar a pandemia de Covid-19, que a autora apresenta abordando as declarações feitas pelos dois grupos e relacionando as principais ações propostas.

Bermudez afirma que, mesmo em um contexto de questionamento do multilateralismo, a Organização dos Estados Americanos (OEA), com grande apoio dos EUA e do Brasil, tem estado ativa no desenvolvimento de uma resposta à pandemia por intermédio de seus diversos órgãos, como a Secretaria-Geral, o Conselho Permanente, o Conselho Interamericano de Desenvolvimento Integral, a Comissão Interamericana de Direitos Humanos, a Comissão Interamericana de Mulheres, além, é claro, da Organização Pan-Americana da Saúde, que também é o organismo regional especializado em saúde do Sistema Interamericano. 
Desde o início da propagação do Sars-Cov2 nas Américas, esses distintos órgãos da OEA adotaram resoluções, emitiram dezenas de comunicados, diretrizes, publicaram guias, organizaram dezenas de seminários virtuais, criaram repositórios de boas práticas e monitoramento da resposta dos países-membros, entre outras atividades com o objetivo de apoiar os países da região na implementação de respostas e políticas públicas com enfoque nos direitos humanos, inclusivas e acessíveis.

Tobar e Linger analisam a resposta da América Latina e Caribe à Covid- 19, abordando seus aspectos sanitários e econômico-sociais e as medidas implementadas pelos países da região. Para tanto, examinam as declarações, orientações e ações comuns implementadas pela Opas e pelos organismos multilaterais (ou plurilaterais) subregionais, casos da Comunidade de Estados Latino-Americanos e Caribenhos (Celac), do Mercado Comum do Sul (Mercosul), do Organismo Andino de Saúde, do Sistema de Integração Centro-Americano e do Mercado Comum e Comunidade do Caribe (Caricom). E concluem que não será fácil superar a difícil situação que permanecerá no cenário pós-pandêmico se não se fizer uso da diplomacia e da cooperação em saúde e não se aprofundarem os processos de integração regional.

Conforme reporta Hoirisch, o Brics vem, desde o início da pandemia, se reunindo para discutir a Covid-19. O grupo, com $40 \%$ da população e $24 \%$ da riqueza, tem um quinto das mortes no mundo. A autora mostra a resposta de cada país do grupo à Covid-19, destacando o contexto político e os compromissos adotados. Discute a crise China-EUA e a importância do multilateralismo para o grupo. Analisa a cooperação entre os Brics e os extra-Brics. O grupo não representa uma região geográfica específica, constitui uma comunidade de interesses econômicos e políticos comuns, tem uma agenda transnacional com diversas áreas de cooperação e projetos de pesquisa no campo da saúde, com mais iniciativas bilaterais e regionais do que multilaterais. A maioria dos países do Brics tem capacidade tecnológica na área de insumos de saúde e o grupo pode avançar na implementação de um centro de pesquisa em vacinas, estabelecer parcerias entre os fundos que apoiam projetos de pesquisa em cada país e criar um programaquadro do Brics, nos moldes da União Europeia.

Silva e Rosenberg tratam da resposta do continente africano e suas instituições à pandemia de Covid-19. As doenças transmissíveis e as recorrentes epidemias no continente africano levaram a União Africana a criar a sua própria agência especializada em saúde pública, o Centro de Controle e Prevenção de Doenças (CDC África), fruto de cooperação com a OMS e os CDC da China, dos EUA e da União Europeia.

O CDC África, criado oficialmente em 2017, enfrenta a sua primeira pandemia e é chamado a coordenar as ações de resposta à Covid- 19 num continente com 55 países. 
A União Africana é estruturada por oito organizações da integração econômica, das quais seis estão mobilizadas e preparadas para responder à pandemia. A cooperação internacional, reunida em torno da OMS, respondeu ao apelo da União Africana, e o CDC África pode se beneficiar de grandes apoios, no continente e internacionalmente.

Os Países Africanos de Língua Portuguesa (Palop), implicados na implementação da Estratégia Africana de Resposta à Covid-19, podem também contar com a colaboração e solidariedade de todos os Estados-membros da Comunidade dos Países de Língua Portuguesa (CPLP) sob a coordenação da Direção de Cooperação do Secretariado Executivo desta organização, partilhando, através de reuniões virtuais, conhecimento e experiências necessários para o enfrentamento da Covid- 19.

Freire, Castro e Vilardo reúnem as principais medidas do bloco europeu para o combate à Covid- 19 tomadas no período de janeiro a julho de 2020, sob a ótica do multilateralismo. As autoras comentam a evolução da pandemia no continente e, em seguida, os esforços conjuntos nas áreas da saúde, da ciência e tecnologia, da economia e da diplomacia empreendidos por diferentes atores e instâncias regionais europeus, bem como suas articulações e iniciativas para enfrentamento da crise. Por fim, abordam a atuação da Europa no cenário internacional, alguns avanços alcançados e lições aprendidas.

Marques analisa as regiões da Ásia-Pacífico (AP) e do Oriente Médio (OM), que reúnem mais de 65 países e mais de um quarto da população mundial, com grande diversidade cultural, religiosa, socioeconômica e política. Esses países têm similaridades quanto às fragilidades dos sistemas de saúde, mas vivem realidades diferentes ((trabalhadores migrantes na AP e refugiados no OM); diferentes fontes econômicas (petróleo no OM e turismo, tecnologia e insumos estratégicos na AP). Várias fragilidades foram trazidas à tona: megafavelas urbanas, trabalhadores migrantes, refugiados, sistemas de saúde pouco inclusivos, carga de doenças tratáveis ou evitáveis, fome e desnutrição.

As tendências geoestratégicas foram aceleradas e as respostas, inicialmente sanitárias, evoluíram para ações políticas e estratégicas voltadas para a autossuficiência e para um reposicionamento na nova ordem mundial. As fragilidades econômicas e sociais e de governança, as tensões exacerbadas e as novas tensões que afloraram são fatores importantes para a compreensão do cenário de desafios para os países da AP e do OM durante e após a pandemia, inclusive para paz e segurança.

Em seguida, a coletânea trata de três países-chave no contexto global: Brasil, China e Estados Unidos da América. O capítulo "O Brasil seis meses após a declaração da Covid- 19 como pandemia global" foi escrito com base no Boletim Observatório Fiocruz Covid-19 após 6 meses da pandemia no Brasil. Em sua primeira parte, é analisada a evolução de casos e óbitos por Covid- 19 no Brasil e no mundo, e comparada a situação 
singular do país, com lento crescimento e extenso patamar de transmissão desde junho, à de outros países com elevados números de casos e óbitos, como África do Sul, China, Espanha, EUA, Índia, Itália, México, Reino Unido e Rússia. Em seguida é analisada a organização dos serviços de saúde, mediante um balanço, e são delineadas perspectivas, considerando-se tanto a capilaridade de um sistema universal de saúde que propiciou a uma parte expressiva da população brasileira acometida pela Covid- 19 o acesso a serviços de saúde em diferentes níveis de complexidade quanto as fragilidades desse sistema, acumuladas em função do subfinanciamento e de problemas de gestão. Fragilidades e singularidades do sistema que se expressaram tanto na qualidade do cuidado e na segurança dos pacientes quanto na saúde dos trabalhadores da saúde. Por fim, são analisadas as situações de populações como indígenas e moradores de áreas de favelas, que, em razão de diferentes processos sociais, estão vulneráveis à Covid-19 e apresentam piores indicadores de mortalidade.

A pandemia tornou mais visíveis os avanços no controle e na prevenção de epidemias na China, segundo Lobato. O aumento da capacidade de testagem, o desenvolvimento da ciência nacional e as medidas drásticas de isolamento social fizeram o número total de mortos do país ser inferior ao de vários países desenvolvidos. Sua capacidade de enfrentamento epidêmico foi vista em todas as fases da resposta, do isolamento e sequenciamento do vírus ao desenvolvimento de vacinas. Tal capacidade pode ser atribuída aos sucessivos investimentos do país em ciência e tecnologia, à adesão da população e ao esforço coordenado dos governos central e provinciais. A elevada capacidade instalada do complexo industrial da saúde chinês foi articulada com outras organizações produtivas, garantindo o abastecimento inclusive de mercados estrangeiros. Lobato argumenta que a resposta chinesa foi, do ponto de vista sanitário, soberana e que a cooperação bilateral e multilateral do setor Saúde pode contribuir para o maior engajamento da relação entre Brasil e China.

O mundo do pós-guerra é, em grande medida, produto de um esforço de reconstrução em que os EUA tiveram participação decisiva. Os acordos de Bretton Woods, com a criação do Banco Mundial, do FMl e do Acordo Geral sobre Tarifas e Comércio (Gatt), são apenas alguns exemplos. Mais importante talvez tenha sido a formação e a posterior consolidação do sistema das Nações Unidas como instrumento para o equacionamento de soluções para problemas globais. Com o surgimento da Covid-19, esperava-se do multilateralismo uma resposta à altura. O que se tem visto, contudo, é um desmantelamento institucional, em grande medida levado a efeito pelo presidente dos EUA, Donald Trump. O problema é que para a Covid- 19 não haverá solução que não seja pela via multilateral. Ninguém estará salvo se todos não estiverem 
salvos, segundo Alcázar, no seu capítulo sobre a resposta dos EUA à pandemia, que encerra a Parte II da coletânea.

A Parte III deste volume é dedicada à substantiva contribuição da Fundação Oswaldo Cruz (Fiocruz) e seus institutos à resposta à pandemia, por meio da cooperação internacional bi e multilateral e da atuação de seus dirigentes, líderes e pesquisadores em instituições globais.

No capítulo de Freire e colaboradores apresenta-se a expressiva ação de cooperação internacional da Fiocruz no contexto da pandemia de Covid-19. A presidência da instituição - incluindo suas vice-presidências e coordenaç̧̃es especializadas - e todos os seus institutos têm realizado intenso trabalho de cooperação com o sistema das Nações Unidas, o sistema plurilateral regional e as instituições coirmãs da América Latina e África, além de instituições e laboratórios da Europa e dos EUA. Junto com Câmara Técnica de Cooperação Internacional da Fiocruz, que coordena o trabalho de cooperação em cada um de seus institutos e nas instâncias da presidência, foi feito um levantamento e as informações foram distribuídas segundo as grandes áreas de atuação da instituição, como pesquisa, educação, informação e comunicação, vigilância, assistência e outras. O volume e a qualidade dos resultados apenas reafirmam a importância conferida pela Fiocruz à cooperação internacional, estratégia que beneficia todos os lados envolvidos, sob a consigna "cooperação estruturante em saúde".

Tobar e colaboradores abordam a estratégia de redes estruturantes na cooperação internacional da Fiocruz, nos âmbitos da América Latina e da CPLP. No cenário atual, em que a Covid-19 traspassa as fronteiras dos países, globalizando os riscos sanitários, sociais e econômicos, o trabalho em rede se apresenta como importante estratégia para a cooperação em saúde. O trabalho em rede reúne diferentes atores que se agrupam voluntariamente, permitindo sua articulação e possibilitando a troca e a conjugação de esforços, experiências e conhecimentos para o alcance de objetivos ou soluções comuns. Desde 2009, a Fiocruz tem fomentado a criação de diversas redes estruturantes que se orientam para o desenvolvimento institucional dos sistemas de saúde dos países parceiros, tais como as redes de Institutos Nacionais de Saúde e as de Formação em Saúde Pública e de Educação Técnica em Saúde. Com a pandemia, essas redes mostram como vêm potencializando sua atuação por meio virtual, adaptando seu trabalho à realidade e promovendo um importante movimento de troca e acúmulo de conhecimentos necessários ao combate à Covid- 19.

Segundo Horton (2020), a pandemia de Covid- 19 vai mudar sociedades, governos, pessoas, a medicina e a ciência. Desejaríamos que para muito melhor: que surgisse um mundo menos desigual, mais inclusivo, mais humano, mais cooperativo e com 
maior respeito ao meio ambiente. Tudo isso depende das pessoas, mas também das nações e da política. Estamos todos indelevelmente juntos na grande nave planetária; portanto, as diferenças políticas entre os países precisam ser superadas para que uma nova era surja no multilateralismo, que seja solidário, cooperativo e justo. Para isso trabalhamos na Fiocruz!

A elaboração deste livro foi uma das mais gratificantes produções coletivas de que os autores participaram. Foram 15 semanas de encontros regulares, em que nitidamente se sentia o crescimento de cada um dos integrantes e do coletivo, assim como da qualidade de cada produto.

Como subproduto deste livro virtual, duas outras fontes de informação estão disponibilizadas: os 15 informes semanais, que dão aos interessados um panorama global, regional e institucional de cada semana da pandemia, desde a primeira semana de abril, quando esse processo foi iniciado. O segundo produto é um volume que reúne os relatos dos autores sobre o que se passou nas 15 semanas em cada uma das instituições ou regiões focalizadas.

Portanto, além deste volume virtual, que sintetiza todo o processo, o Cris produziu 15 informes semanais globais e 13 informes institucionais ou regionais. É um notável esforço, feito com grande satisfação e dedicação, pelo serviço que acreditamos estar prestando à instituição a que servimos, bem como à comunidade de saúde e diplomacia nacional e global, com quem temos mantido produtivo diálogo e cooperação.

A publicação deste livro não teria sido possível sem a decisiva contribuição dos membros da Câmara Técnica de Cooperação Internacional em Saúde da Fiocruz, a quem dedicamos reconhecimento por sua contribuição na integração das relações internacionais da Fiocruz, por meio de todas as suas unidades técnicas: Aldo Venâncio (IRR), Analice Braga (Vpeic), Bárbara Trigueiros (ICC), Carlos Eduardo Grault (VPPCB), Carlos Eduardo Rocha (IOC), Claudia Chamas (CDTS), Cristiano Boccolini (Icict), Cristina Guilam (Vpeic), Eleonora Vasconcellos (INCQS), Emmanuelle Batista (Cris), Fabiane Gaspar (COC), Felippe Amarante (Ensp), Flavia Paixão (IGM), Gabriela Lobato (VPAAPS), Guilherme Franco Neto (VPAAPS), Helifrancis Condé (EPSJV), Ivana Barreto (Fiocruz-CE), João Aprígio (IFF), José Paranaguá (Gereb), Julia Rodrigues (CCS), Marcos Targino (Farmanguinhos), Maria da Penha (IAM), Maria Mendes Gomes (IFF), Norma Brandão (IOC), Patrícia Santana (Bio-Manguinhos), Pedro Burger (Ensp), Rafaella Queiroz (IRR), Roberta Freitas (Gereb), Sandra Soares (VPPIS), Tiago Neri (INI), Valber Frutuoso (Presidência), Wilson Savino (Coordenação Regional). 
Este livro também não teria se materializado sem a colaboração da equipe técnica que apoia o trabalho do Cris, solidária em todos os momentos: Cláudia Parente (coordenadora de Gestão), Anderson Nascimento, Barbara Vieira, Ana Paula Apolônio, Mary Fermo, Helena Distelfeld (coordenadora de Convênios e Mobilidade), Emmanuelle Batista, Liliane Botelho, Daniel Ferreira, Milton Lopes, Domingos Esteves, Gabriela Dutra, Luciana Ferreira, Sabrina Lopes, Elen Militão, Marcella Antunes e Guilhermina Duarte.

Agradecemos ainda o importante e constante apoio da Presidência da Fiocruz, na pessoa de sua presidente, Nísia Trindade, e de todas vice-presidências e suas coordenações, assim como os comentários de incentivo dos diversos líderes da Fiocruz que receberam (e continuam recebendo), ao longo das semanas, os informes sobre a resposta global à pandemia para os utilizarem como subsídios em suas decisões. Esse retorno nos incentivou a publicar nesta coletânea o consolidado das semanas por região.

Uma palavra especial de agradecimento à Editora Fiocruz, nas figuras da sua dinâmica diretora, Cristiani Vieira Machado, e do seu competente editor executivo, João Carlos Canossa Mendes, prata da casa e responsável há mais de vinte anos por conduzir a editora pelos caminhos que encarnam o espírito da instituição, que é o de servir com qualidade aos brasileiros, à ciência e ao SUS.

\section{REFERÊNCIAS}

FREITAG, M. On the endangered list: the "instant book". The New York Times, New York, Nov. 1 5, 1987. Section 3, p. 12.

HOBSBAWM, E. Era dos Extremos: o breve século XX, 1914-199I. São Paulo: Companhia das Letras, 1995. HORTON, R. The Covid-I 9 Catastrophe. Cambridge: Polity Press, 2020a.

HORTON, R. Offline: Covid- I 9 is not a pandemic. The Lancet (I0255), 2020b. ISSN 0I40-6736. PMID 32979964. doi:10.1016/s0140-6736(20)32000-6.

OPAS (2020). Entenda a infodemia e a desinformação na luta contra a Covid-19. Página informativa n. 5. Disponível em: <https://iris.paho.org/bitstream/handle/I0665.2/52054/Factsheet-Infodemic_ por.pdf? sequence $=14>$. Acesso: 16 out. 2020.

WORLD HEALTH ORGANIZATION (WHO). Covid- I 9, global literature on coronavirus disease. Disponível em: <https://search.bvsalud.org/global-literature-on-novel-coronavirus-20 I9-ncov/>. Acesso em: I 8 set. 2020 . 